\title{
Gene Therapy for Type 1 Diabetes
} Is it Ready for the Clinic?

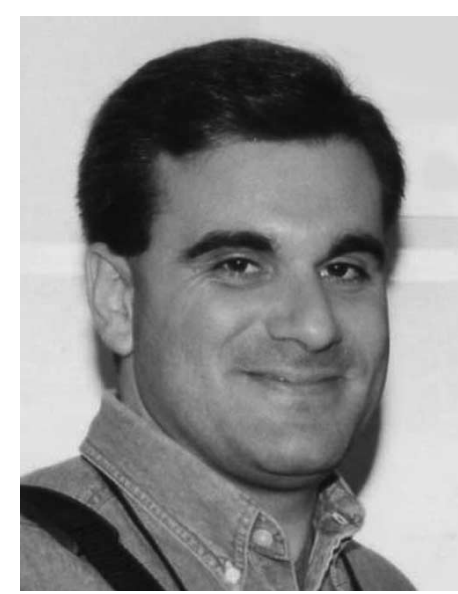

\section{Abstract}

This review, in addition to updating the growing list of type 1 diabetes-relevant gene therapies, offers an outline of short-term objectives that can readily be met to move, at least, adenoviral and adeno-associated viral-based protocols into the clinic, first as a means of facilitating islet allografts as well as platforms with which to introduce immunoregulatory transgenes. A wide array of genes have been tested to restore insulin production, to drive the differentiation of insulin-producing progenitors, and to confer immunosuppression in an antigen- and tissue-restricted manner.

\section{Key Words}

Diabetes

Gene therapy

Immunotherapy

Autoimmunity

Antonella D’Anneo ${ }^{1,2,3}$ Pleunie Rood ${ }^{1,2}$ Rita Bottino $^{1,2}$

A.N. Balamurugan ${ }^{1,2}$ Jing $\boldsymbol{H e}^{1,2}$ Nick Giannoukakis ${ }^{1,4}$

${ }^{1}$ Diabetes Institute, Children's Hospital of Pittsburgh, Pittsburgh, PA, USA; ${ }^{2}$ Department of Pediatrics, Division of Immunogenetics, University of Pittsburgh School of Medicine, Pittsburgh, PA, USA; ${ }^{3}$ Department of Biochemical Sciences, University of Palermo, Palermo, Italy; ${ }^{4}$ Department of Pathology, University of Pittsburgh School of Medicine, Pittsburgh, PA, USA
Diabetes mellitus affects approx 17 million people in the United States (approx 6.3\% of the entire American population) and based on this scenario its prevalence is increasing to likely epidemic proportions by 2050 (1). On the basis of recent data, the disease accounts for about one sixth of all expenditures for health care (2). In type 1 diabetes, the beta cells of the pancreas fail to produce enough insulin to meet the body's demand because the immune system selectively inhibits the function and then destroys the islet beta cells (3). Type 1 diabetics, therefore, must manage their disease by following a regulated-diet, exercise plan, and replacing insulin by daily injections or insulin pump. While insulin replacement has drastically improved the lifespan of diabetics, its administration fails to
Address all correspondence to:

Nick Giannoukakis, PhD, Department of Pathology, University of Pittsburgh School of Medicine, Diabetes Institute, Rangos Research Center, 3460 Fifth Avenue, Pittsburgh, PA 15213. E-mail: ngiann1@ @itt.edu 36/0:000-000/\$30.00 
mimic its physiologic regulation and that of glucoregulation in the body. Although multiple clinical trials have shown that insulin replacement can delay the life-threatening complications of diabetes, it by no means can be considered a cure.

Given the pivotal role of beta cell mass in determining whether an individual will progress to type 1 diabetes (3), serious efforts have been under way for $20 \mathrm{yr}$ to identify alternative means of improving glycemic control in diabetic patients. The major advance that is now clinically acceptable and, to a degree, successful, offering a potential cure for type 1 diabetes is the transplantation of islets of Langherans (4). Islet transplants, however, are limited by the availability of donors and their initial function following transplantation is challenged by apoptotic cell death that generally occurs during the isolation process and immediately following transplantation. Furthermore, transplant patients have to receive long-term-probably lifetime-immunosuppression therapy with all its associated side-effects.

A considerable number of studies demonstrate the feasibility of using viral gene delivery vehicles to import transgenes into intact islets ex vivo with the aim of facilitating their transplantation, function, and resilience against alloimmune rejection and autoimmune impairment/destruction (5-8). The transgenes fall into three broad categories: those that encode soluble proteins interacting with infiltrating immune cells, those that encode intracellular prosurvival/antiapoptotic proteins, and those that encode differentiation factors for beta cell progenitors. At the other end of the spectrum are methods that rely on systemic production of factors that promote immune cell regulation (either by enhancing the number and activity of regulatory $T$ cells or by attenuating the effects of antigraft immune cells, for example). We have recently published a list of transgenes successfully employed to date in facilitating islet allograft survival and/or promoting networks of immune cell hyporesponsiveness to allografts or autoimmunity suppression (reviewed in refs. 5-8).

Perusing those studies, it is obvious that the most widely used gene vectors are adenovirus (Ad) and adeno-associated virus (AAV). The former transfer vehicle is often E1-deleted and in some instances E1- and E3- or E1/E4deleted (9-17). The question raised by many is whether it is prime time to begin testing these vectors in safety trials in humans.

There are two key concerns that previous safety trials in humans raise: vector toxicity to transduced tissue and anti-vector responses (9-17). These two concerns are crucial for attempts to administer transgenes systemically in humans. We believe, however, that ex vivo transduction of cells and tissues followed by transplantation, may not carry the risks and dangers associated with systemic administration. First, the ex vivo approach involves considerable washing of the vector along with cells that may be apoptotic and dysfunctional. This has the twofold effect of removing much of the non-specifically adherent vector that has not been internalized and removes the "danger" signals that the host immune system sees in apoptotic cells of allogeneic origin. Therefore, we propose that ex vivo transduction of allogeneic islets of Langerhans with adenoviral vectors is ready for prime time.

$\mathrm{AAV}$, on the other hand, offers additional attractive features in that some serotypes are less immunogenic than others and certainly less so than adenoviral vehicles (18-31). The possibility of AAV integration into the host genome is also an attractive feature that could ensure long-term transgene persistence in vivo following transplantation of ex vivo-engineered islets of Langerhans for example. 
Although limited, recent studies are beginning to confirm the utility of direct intrapancreatic vector administration for diabetes therapy, originally reported a decade ago (32) and improved more recently (33-35). Along these lines, a recent study by Bosch and colleagues (36) is important in two respects. First, it confirmed those few early reports $(32,37,38)$ demonstrating that direct in vivo delivery of a viral vector into the pancreas achieves reasonable transduction of pancreatic cells (that may include potential stem cells developing into endocrine cells) and second, and most importantly, it should raise serious considerations that it is time for the field to move away from mice and into larger animals. Embedded in the study by Bosch and colleagues is preliminary reassurance that adenoviral vector transduction of the endogenous pancreas may not be associated with the inflammatory and toxic effects shown in a plethora of liver-directed gene therapies and the Gelsinger case a few years ago $(39,40)$. It is no secret that the immune system, the biochemistry, and the physiology of mice and man are not identical. Extrapolating therapeutic success from mouse models to humans can be misleading without an intermediate step of testing the therapy in large animals. In fact, it may be time to consider completely bypassing rodents, when the in vitro data are overwhelmingly convincing.

Transplantation of gene-modified islets and direct intrapancreatic gene transfer fall inside this category of "rodent-bypassing" lines of investigation. Chemical immunosuppression required to prevent allogeneic islet rejection has been directly implicated in beta cell functional impairment (41-43) and significantly impedes the immune capacity of the recipient at a systemic level. Gene-engineered islets may offer local immunoregulatory effects without impairing the immune system systemically, although this has not yet been completely and convincingly formally proven. Furthermore, islets may be engineered in such a way as to direct local immune hyporesponsiveness in addition to providing trophic stimuli for endocrine stem cell differentiation, especially if the transplant is placed inside a site with endocrine stem cell potential. Direct intrapancreatic administration of gene vectors may not result in as precise a distribution of transgene product as that produced by a transplant, but it offers the potential for minimal trauma to the transduced tissue (unlike ex vivo transduced islets which are often infected by many particles per cell). In this context, large animals offer procedural ease; the liver of a rhesus monkey is considerably larger than that of a mouse, and monkey pancreata are more readily manipulatable.

New accumulating evidence suggests that once autoimmunity is abrogated the endocrine pancreas properties may be sufficient to allow the physiological regenerative process to restore endogenous insulin production (44-48) even after the disease has become clinically manifest (49-52). The physiologic regenerative potential of the endocrine pancreas seems to be still quite high immediately after (or very close to) the onset of the disease when, in general, there still are some insulin-producing cells able to secrete sufficient insulin to make C-peptide testing possible, i.e., over the minimum level detectable by the appropriate assays (53). In the mouse and possibly in the monkey (e.g., cynomolgus), the regenerative process seems to take more than 3 mo to substitute enough beta cells to allow the detection of an influence on the control of the glycemia of the animal. Even at this point in time, both of these animals do not yet have perfect control of the glycemia, because intravenous glucose tolerance tests (IVGTTs) are still far from normal. However, this result would already constitute a great advantage for the 


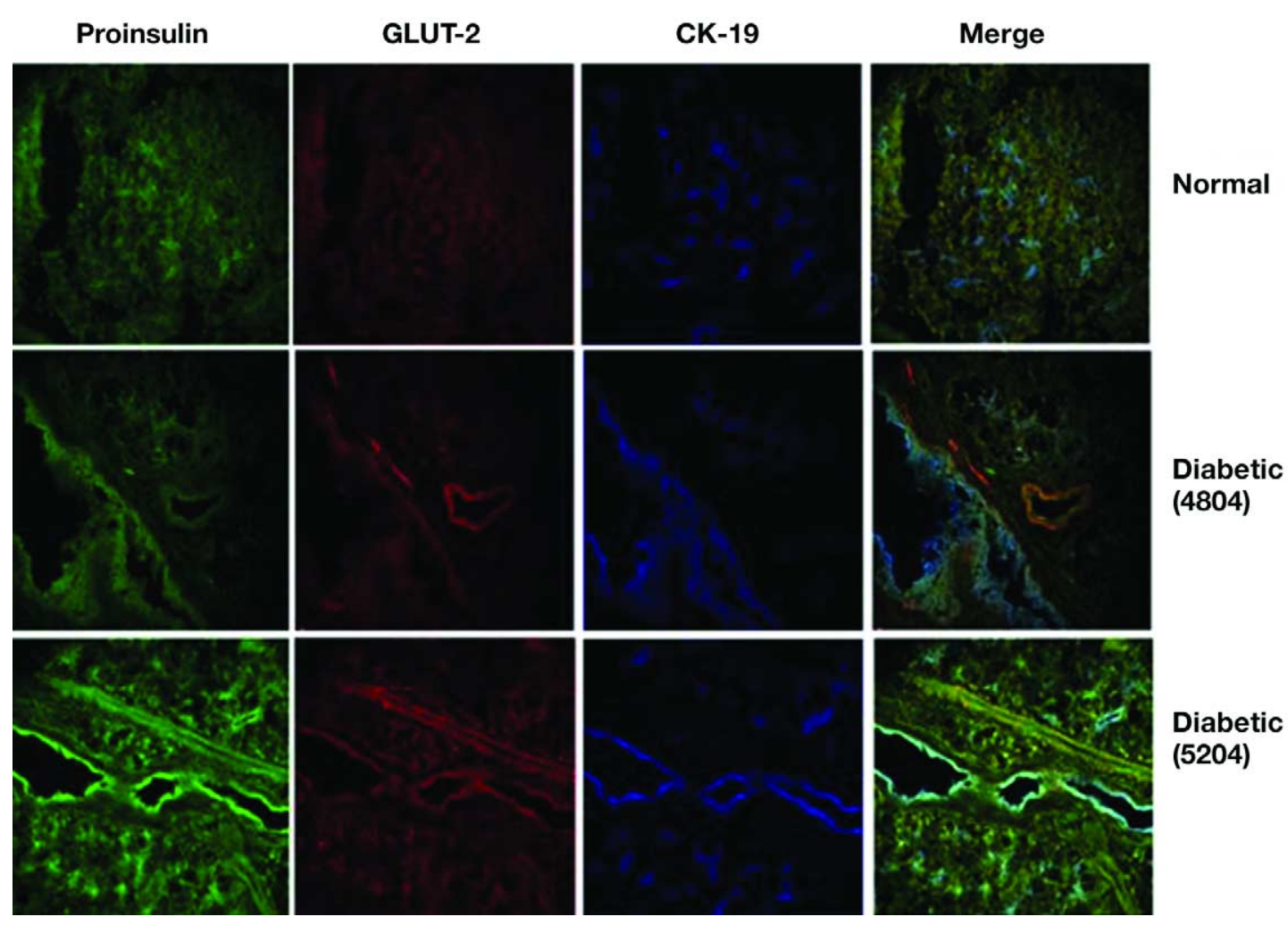

Fig. 1. Regeneration of endocrine tissue in the pancreas of diabetic rhesus monkeys. Pancreata from normal (top row) or streptozotocin-induced diabetic rhesus monkeys (second and third row) were obtained, fixed, sectioned, and then stained with antibodies specific for proinsulin (green), GLUT-2 glucose transporter (red), and cytokeratin-19 (CK19) - a marker of ductal epithelium from which endocrine progenitor cells appear to arise (blue). Magnification 40×. Co-staining of all three proteins in diabetic pancreata and co-localization of cytokeratin-19 and proinsulin along with GLUT-2 (beta cell-specific glucose transporter) suggests a common origin of insulin-producing cells from a ductal epithelial progenitor in a regenerative process.

diabetic patient, even if we do not know for sure whether, at a longer time after clinical onset, the reparative process may still work and at the same speed observed immediately after onset. Preliminary studies in animals seem to indicate that the regenerative process works proportionally more slowly as the time from onset of the disease increases (54). In Fig. 1, we show the regenerative process at work in diabetic rhesus monkeys.

To help the system to activate the regenerative process or to speed up a possibly very slow physiologic recovery, even after pro- tracted diabetes insulin therapy, it would be useful to test different factors that have been proven to be efficient in better achieving this goal $(55,56)$. For other factors, like PAX4 (57), HGF (58), IGF-1 $(59,60)$, or GLP-1 (61), the insulin promoter should be used to construct the cassettes eventually introduced into the vector. In a recent study (35), the capacity of adeno-associated-virus (AAV)-mediated pancreatic gene transfer was reexamined using the recently available novel serotypes of AAV coupled with an improved double-stranded AAV vector DNA cassette, which facilitates 
rapid and stronger transgene expression (62). It has been shown that robust and long-term gene transfer can be achieved by these vectors in the vast majority, if not all, of the islets. Gene transfer efficiency and vector distribution in the islets are determined by the choice of AAV serotype vectors, as well as by the delivery methods. The pancreatic exocrine acinar cells are highly susceptible to AAV8 infection. To minimize the unwanted gene transfer to non-endocrine pancreatic and nonpancreatic tissues seen after ip or iv delivery, we explored a topical route by retrograde delivery into the pancreatic duct, similar to the ERCP (endoscopic retrograde cholangio-pancreatography) technique commonly used in patients with pancreatitis. Because the pancreatic beta cell is, by definition, the most important target in gene transfer and therapy for diabetes, we explored the use of the insulin promoter to minimize non-specific transgene expression in unintended cells, such as the pancreatic acinar cells and those beyond the pancreas. As expected, 2 wk after delivery of AAV8-insulin-promoter-GFP vector in adult mice, strong GFP expression was readily detected exclusively in the islets, but not in the exocrine acinar cells (35).

In the rapidly shifting priorities of research support for diabetes, translational research toward therapy has not kept pace with the explosive discoveries in the field of molecular investigation. This is most true for gene therapy for diabetes. Third and fourth generation viral vectors are now available with low-to-zero potential for immunogenicity. A large array of transgenes awaits to be transferred into islets for subsequent transplantation and/or directly injected into the pancreas to promote the survival of residual beta cell mass and to direct the differentiation of stem cells into endocrine cells in situ. The mouse will always serve its function as the proving ground; however, the large animal will validate this proving ground. In this regard, the study by Bosch and colleagues (36) should at the very least challenge the diabetes gene therapy community to seriously consider bypassing the mouse, when it is obvious that a large animal model offers a physiologic and immunologic environment closer to humans and a rational host for humandirected therapies.

\section{References}

1. Boyle JP, Honeycutt AA, Narayan KM, et al: Projection of diabetes burden through 2050: impact of changing demography and disease prevalence in the U.S. Diabetes Care 2001;24:1936-1940.

2. LeRoith D, Smith DO: Monitoring glycemic control: the cornerstone of diabetes care. Clin Ther 2005;27:1 489-1499.

3. Faideau B, Larger E, Lepault F, Carel JC, Boitard C: Role of \{beta\}-cells in type 1 diabetes Pathogenesis. Diabetes 2005;54(Suppl 2):S87-96.

4. Bottino R, Trucco M: Multifaceted therapeutic approaches for a multigenic disease. Diabetes 2005; 54:S79-S86.

5. Giannoukakis N, Robbins PD: Gene and cell therapies for diabetes mellitus: strategies and clinical potential. BioDrugs 2002;16:149-173.
6. Bottino R, Lemarchand P, Trucco M, Giannoukakis N: Gene- and cell-based therapeutics for type I diabetes mellitus. Gene Ther 2003;10:875-889.

7. Giannoukakis N, Trucco M: Gene therapy technology applied to disorders of glucose metabolism: promise, achievements, and prospects. Biotechniques 2003;35: 122-145.

8. Giannoukakis N, Trucco M: Current status and prospects for gene and cell therapeutics for type 1 diabetes mellitus. Rev Endocr Metab Disord 2003;4:369-380.

9. Kovesdi I, Brough DE, Bruder JT, Wickham TJ: Adenoviral vectors for gene transfer. Curr Opin Biotechnol 1997;8:583-589.

10. Yeh P, Perricaudet M: Advances in adenoviral vectors: from genetic engineering to their biology. FASEB J 1997;11:615-623. 
11. Kochanek S: Development of high-capacity adenoviral vectors for gene therapy. Thromb Haemost 1999; 82:547-551.

12. Kochanek S: High-capacity adenoviral vectors for gene transfer and somatic gene therapy. Hum Gene Ther 1999; 10:2451-2459.

13. Seth P: Adenoviral vectors. Adv Exp Med Biol 2000; 465:13-22.

14. St George JA: Gene therapy progress and prospects: adenoviral vectors. Gene Ther 2003;10:1135-1141.

15. Cao H, Koehler DR, Hu J: Adenoviral vectors for gene replacement therapy. Viral Immunol 2004;17:327-333.

16. Schagen FH, Ossevoort M, Toes RE, Hoeben RC: Immune responses against adenoviral vectors and their transgene products: a review of strategies for evasion. Crit Rev Oncol Hematol 2004;50:51-70.

17. Volpers C, Kochanek S: Adenoviral vectors for gene transfer and therapy. J Gene Med 2004;6 Suppl 1:S164-171.

18. Lai CM, Lai YK, Rakoczy PE: Adenovirus and adenoassociated virus vectors. DNA Cell Biol 2002;21:895-913.

19. Grimm D, Kay MA: From virus evolution to vector revolution: use of naturally occurring serotypes of adenoassociated virus (AAV) as novel vectors for human gene therapy. Curr Gene Ther 2003;3:281-304.

20. Stilwell JL, Samulski RJ: Adeno-associated virus vectors for therapeutic gene transfer. Biotechniques 2003;34:148-150, 152, 154 passim.

21. Sun JY, Anand-Jawa V, Chatterjee S, Wong KK: Immune responses to adeno-associated virus and its recombinant vectors. Gene Ther 2003;10:964-976.

22. Buning H, Braun-Falco M, Hallek M: Progress in the use of adeno-associated viral vectors for gene therapy. Cells Tissues Organs 2004;177:139-150.

23. Carter BJ: Adeno-associated virus and the development of adeno-associated virus vectors: a historical perspective. Mol Ther 2004;10:981-989.

24. Conlon TJ, Flotte TR: Recombinant adeno-associated virus vectors for gene therapy. Expert Opin Biol Ther 2004:4:1093-1101.

25. Daly TM: Overview of adeno-associated viral vectors. Methods Mol Biol 2004;246:157-165.

26. Flotte TR: Gene therapy progress and prospects: recombinant adeno-associated virus (rAAV) vectors. Gene Ther 2004;11:805-810.

27. McCarty DM, Young SM, Jr, Samulski RJ: Integration of adeno-associated virus (AAV) and recombinant AAV vectors. Annu Rev Genet 2004;38:819-845.

28. Wang CH, Liu DW, Tsao YP, Xiao X, Chen SL: Can genes transduced by adeno-associated virus vectors elicit or evade an immune response? Arch Virol 2004;149:1-15.

29. Romano G: Current development of adeno-associated viral vectors. Drug News Perspect 2005;18:311-316.

30. Snyder RO, Francis J: Adeno-associated viral vectors for clinical gene transfer studies. Curr Gene Ther 2005; 5:311-321.

31. Zaiss AK, Muruve DA: Immune responses to adeno-associated virus vectors. Curr Gene Ther 2005;5:323-331.
32. Raper SE, DeMatteo RP: Adenovirus-mediated in vivo gene transfer and expression in normal rat pancreas. Pancreas 1996;12:401-410.

33. Flotte T, Agarwal A, Wang J, et al: Efficient ex vivo transduction of pancreatic islet cells with recombinant adenoassociated virus vectors. Diabetes 2001;50:515-520.

34. Loiler SA, Tang Q, Clarke T, et al: Localized gene expression following administration of adeno-associated viral vectors via pancreatic ducts. Mol Ther 2005; 12:519-527.

35. Wang Z, Zhu T, Rehman KK, et al: Widespread and stable pancreatic gene transfer by AAV vectors via different routes. Diabetes 2006;55:875-884.

36. Ayuso E, Chillon M, Garcia F, et al: In vivo gene transfer to healthy and diabetic canine pancreas. Mol Ther 2005;13:747-755.

37. McClane SJ, Chirmule N, Burke CV, Raper SE: Characterization of the immune response after local delivery of recombinant adenovirus in murine pancreas and successful strategies for readministration. Hum Gene Ther 1997;8:2207-2216.

38. Shifrin AL, Auricchio A, Yu QC, Wilson J, Raper SE: Adenoviral vector-mediated insulin gene transfer in the mouse pancreas corrects streptozotocin-induced hyperglycemia. Gene Ther 2001;8:1480-1489.

39. Couzin J, Kaiser J: Gene therapy. As Gelsinger case ends, gene therapy suffers another blow. Science 2005;307:1028.

40. Somia N, Verma IM: Gene therapy: trials and tribulations. Nat Rev Genet 2000;1:91-99.

41. Hirano Y, Mitamura T, Tamura T, Ohara K, Mine Y, Noguchi H: Mechanism of FK506-induced glucose intolerance in rats. J Toxicol Sci 1994;19:61-65.

42. Uchizono Y, Iwase M, Nakamura U, Sasaki N, Goto D, Iida M: Tacrolimus impairment of insulin secretion in isolated rat islets occurs at multiple distal sites in stimulussecretion coupling. Endocrinology 2004;145:2264-2272.

43. Shapiro AM, Geng Hao E, Lakey JR, Finegood DT, Rajotte RV, Kneteman NM: Defining optimal immunosuppression for islet transplantation based on reduced diabetogenicity in canine islet autografts. Transplantation 2002;74:1522-1528.

44. Bonner-Weir S, Sharma A: Pancreatic stem cells. J Pathol 2002;197:519-526.

45. Seaberg RM, Smukler SR, Kieffer TJ, et al: Clonal identification of multipotent precursors from adult mouse pancreas that generate neural and pancreatic lineages. Nat Biotechnol 2004;22:1115-1124.

46. Suzuki A, Nakauchi H, Taniguchi H: Prospective isolation of multipotent pancreatic progenitors using flowcytometric cell sorting. Diabetes 2004;53:2143-2152.

47. Trucco M: Regeneration of the pancreatic beta cell. J Clin Invest 2005;115:5-12.

48. Bonner-Weir S, Toschi E, Inada A, et al: The pancreatic ductal epithelium serves as a potential pool of progenitor cells. Pediatr Diabetes 2004;5(Suppl 2):16-22.

49. Zorina TD, Subbotin VM, Bertera S, et al: Recovery of endogenous beta cell function in autoimmune diabetes. Stem Cells 2003;21:377-388. 
50. Zorina TD, Subbotin VM, Bertera S, et al: Distinct characteristics and features of allogeneic chimerism in the NOD mouse model of autoimmune diabetes. Cell Transplant 2002;11:113-123.

51. Solimena M, Dirkx R, Jr, Hermel JM, et al: ICA 512, an autoantigen of type I diabetes, is an intrinsic membrane protein of neurosecretory granules. EMBO J 1996; 15:2102-2114.

52. Ikehara S, Ohtsuki H, Good RA, et al.: Prevention of type I diabetes in nonobese diabetic mice by allogenic bone marrow transplantation. Proc Natl Acad Sci USA 1985;82:7743-7747.

53. von Herrath M, Homann D: Islet regeneration needed for overcoming autoimmune destruction-considerations on the pathogenesis of type 1 diabetes. Pediatr Diabetes 2004;5(Suppl 2):23-28

54. Rood PP, Bottino R, Balamurugan AN, Fan Y, Cooper DK, Trucco M: Facilitating physiologic self-regeneration: a step beyond islet cell replacement. Pharm Res 2006;23:227-242.

55. Suarez-Pinzon WL, Yan Y, Power R, Brand SJ, Rabinovitch A: Combination therapy with epidermal growth factor and gastrin increases \{beta\}-cell mass and reverses hyperglycemia in diabetic NOD mice. Diabetes 2005;54:2596-2601.

56. Baeyens L, De Breuck S, Lardon J, Mfopou JK, Rooman I, Bouwens L: In vitro generation of insulin-producing beta cells from adult exocrine pancreatic cells. Diabetologia 2005;48:49-57.

57. Heremans Y, Van De Casteele M, in't Veld P, et al: Recapitulation of embryonic neuroendocrine differentiation in adult human pancreatic duct cells expressing neurogenin 3. J Cell Biol 2002;159:303-312.

58. Garcia-Ocana A, Takane KK, Syed MA, Philbrick WM, Vasavada RC, Stewart AF: Hepatocyte growth factor overexpression in the islet of transgenic mice increases beta cell proliferation, enhances islet mass, and induces mild hypoglycemia. J Biol Chem 2000; 275:1226-1232.

59. George M, Ayuso E, Casellas A, Costa C, Devedjian JC, Bosch F: Beta cell expression of IGF-I leads to recovery from type 1 diabetes. J Clin Invest 2002;109:1153-1163.

60. Guo Y, Lu Y, Houle D, et al: Pancreatic islet-specific expression of an insulin-like growth factor-I transgene compensates islet cell growth in growth hormone receptor gene-deficient mice. Endocrinology 2005;146: 2602-2609.

61. Farilla L, Hui H, Bertolotto C, et al: Glucagon-like peptide1 promotes islet cell growth and inhibits apoptosis in Zucker diabetic rats. Endocrinology 2002;143:4397-4408.

62. Rehman KK, Wang Z, Bottino R, et al: Efficient gene delivery to human and rodent islets with doublestranded (ds) AAV-based vectors. Gene Ther 2005;12: 1313-1323. 